\title{
A Cross-National Study of Motivation in Language Learning
}

\author{
Surina Nayan, Hariharan N. Krishnasamy, and Latisha Asmaak Shafie
}

\begin{abstract}
Motivation plays an important role in one's learning. When one is motivated, he/she will be moved to accomplish the task given to him/her efficiently. The studies on motivation in language learning have contributed a lot to the development of many theories on motivation. In addition, findings from previous research on motivation based on different theories are included in this paper. This paper also focuses on research done on motivation across nations. Recommendations given on how to help learners to be more motivated are also included.
\end{abstract}

Index Terms-Language learning, motivation, self concept and theories of motivation.

\section{INTRODUCTION}

Motivation is one of the areas that has attracted many researchers to explore what drives learners in either their L2 or FL learning settings. Despite the different approaches used to study motivation in learners, its definitions are uniform. This is due to the motivation drive that leads to goal achievement. There are four aspects of motivation that include a goal, an effortful behavior to reach the goal, a desire to attain the goal and positive attitudes toward the goal [1].

Building upon the earlier definitions, motivation also refers to the intensity of one's impetus to learn [2]. Besides, it is also referred to as "...an abstract, hypothetical concept that we use to explain why people think and behave as they do," [3]. In addition, "To be motivated means to be moved to do something," [4]. Thus, it can be concluded that motivation is defined as the forces and also a soft construct that accounts for the arousal, selection, direction, and continuation of behavior that can be inferred rather than observed directly. "No matter what the underlying motivation to study a second language, what cannot be disputed is the fact that motivation is an important variable when examining successful second language acquisition," [5].

There are different types of motivation and theories in Second Language Education which have emerged through years. For example, the integrative and instrumental types of motivation which are under the traditional theories of motivation in L2 education. The two prominent figures in L2 motivation research: Gardner and Lambert came up with their integrative and instrumental orientation of motivation [6]. Integrative motivation relates to learners positive

Manuscript received July 25, 2013; revised November 15, 2013.

Surina Nayan and Asmaak Shafie are with Universiti Teknologi MARA, 02600, Arau, Perlis, Malaysia (e-mail: surinana@perlis.uitm.edu.my, latisha@perlis.uitm.edu.my).

Hariharan N. Krishnasamy is with the College of Arts and Humanities (CAS), Universiti Utara Malaysia (UUM) 06010, Sintok, Kedah, Malaysia (e-mail: hn1084@uum.edu.my). attitudes towards the speakers and culture of the target language. On the contrary, instrumental motivation focuses more on the learners' goals for academic achievement and for career development. Both types, the instrumental and integrative motivation are important in Fl or L2 settings because "an absence of integrative motivation can outweigh instrumental motivation that does exist, halting or severely retarding language learning,"[7].

Although Gardner's theory on integrative and instrumental motivation has contributed much to the research on second language motivation, the theory has been criticized for focusing too much on the integrative motive. Moreover, previous studies done to validate the theory have also produced different results which are controversial [8]. This theory also fails to consider the cognitive motivational concept in motivation. In addition, the label 'integrativeness' did not make much sense in many language learning environments [9].

The other theory introduced is the Self Determination Theory (SDT) which is an empirical based theory of human motivation, development, and wellness [10]. The main focus of this theory is on types rather than the amount of motivation. Autonomous motivation, controlled motivation and amotivation are the predictors of performance, relational and well-being outcomes of this theory. SDT is a meta-theory that accounts for two views with regards to human behaviour. These views are :

1) humans act with a stimulus (agency) and intrinsic motivation

2) humans' actions can be determined or influenced by the external factors surrounding them

Furthermore, according to the SDT theory, activities which are not interesting (which are not intrinsically motivating) require extrinsic motivation. When one's behaviour is so motivated, it is caused by conditions or situations (contigencies) which are external to that person. On the revisit of the intrinsic and extrinsic motivation, it was claimed that intrinsic motivation still remains an important construct in humans [11]. Intrinsic motivation reflects the human learning and assimilation process. On the contrary, extrinsic motivation is argued to reflect one's external or true self-regulation since it varies in terms of its autonomy.

Another most general and well-known motivation theory is that of Vallerand, which includes intrinsic and extrinsic motivation [12]. Intrinsic motivation deals with a sense of self satisfaction of doing some particular activities, while the extrinsic motivation refers to performing activities for some extrinsic reward such as getting a good grade or having a promotion. The theory also includes a third type of motivation which is amotivation (lack of motivation). The Hierarchical Model of Intrinsic and Extrinsic motivation introduced by Vallerand is rather complex. This model 
includes the global level, contextual level and also the situational level that affect one's motivation. The interaction with the environment either intrinsically, extrinsically or in any amotivated way refers to the global motivation. In addition, one's motivation is also affected by the context which she/he is engaging such as in education, interpersonal relationships or leisure. Finally, a person is also affected by the situation that he/she is experiencing like doing activities in the classroom or having a field trip. These hierarchical levels of motivation are also affected by the moderating factors which include autonomy (feeling free to choose one's course of actions), competence (interacting effectively with the environment) and relatedness (feeling connected to significant others).

Nowadays, the notion of 'self' in psychology has been widely and frequently used. "Today, modern 'self' theory says each person is expected to decide what is right (almost by magic and without much reliance on the accumulated wisdom of the culture) and to know him/herself well enough to determine what courses of action 'feel right.' In short, we must know ourselves, so we can set our lives and self actualize," [13].

Recently, L2 motivational self-concept has been introduced to replace and expand previous conceptions of motivation. The model incorporates the Ideal-L2 Self, the Ought-to Self and the L2 Learning Experience. Ideal L2-self is "the L2-specific facet of one's ideal self." It represents an ideal image of what the L2 user wishes to be in the future. If he wishes to be a fluent L2 user, his imagery picture of himself as a fluent L2 user might act as a powerful motivator for him to reduce the discrepancy between his actual and ideal self. The Ought-to L2 self concerns with "the attributes that one believes one ought to possess as a result of perceived duties, obligations or responsibilities,"[14]. Ought-to self is less internalised since it focuses more on the extrinsic type of instrumental motives. The L2 learning experience concerns with learners' attitudes towards their L2 learning. Their attitudes can be affected by situation-specific motives that relate to their learning environment and experience like the peer group, the teacher, their experience of success and also the curriculum.

\section{RESEARCH ON MOTIVATION}

Motivation, according to researchers and teachers, has been accepted as one of the main key factors that affects the rate and success of L2/FL language learning [15]. Reference [16] agree that "it makes sense that individuals who are motivated will learn another language faster and to a great degree." Furthermore, numerous studies have provided statistical evidence that indicates motivation is a predictor of the language learning success.

There are a lot of researchers who have explored on motivation with different learners and situations that have shown different findings that contribute to the study of motivation. For example Samsiah Bidin, Kamarulzaman Jusoff, Nurazila Abdul Aziz, Musdiana Mohamad Salleh \& Taniza Tajudin [17] on their study on motivation and attitude in learning English among UiTM students in the Northern Region of Malaysia find that intrinsic and extrinsic motivation does not have a direct influence on students' English language performance. So does attitude. Nikitina \& Furouka [18] who conducted a survey on the nature of motivation of the Russian Language to 74 first year students at Universiti Malaysia Sabah. For their first survey they find students' academic performance in learning Russian did not depend on their attitudes and did not involve degree of integrativeness towards the target language's speakers or culture. For the second survey they find students acquired a more positive attitude towards -and appreciation of - target language's country and its culture.

Besides, Mun [19] on his investigation on relationships between learners' English proficiency levels and their motivational intensity and motivational orientation (integrative or instrumental) in learners finds that there is no major distinctive difference in terms of motivational orientation among high, average and low English proficiency learners. For all the three proficiency levels, learners were driven by instrumental motivation to learn the language. However, there is evidence that learners who are more proficient have higher motivational intensity towards the language. Female students used overall LLSs more often than male students .

Wei, Tuan Fatma Tuan Sulaiman, Wardah Mohamad \& Zorah Abu Kasim [20] on their research on motivation and study habits of working adults: A case study of Masters students in Open University Malaysia find that learners had different factors that motivate them in their study. Achieving success and wanting to improve themselves are the two motivating factors. Respondents also received support from their family and friends. Surprisingly, none of the respondents mentioned that their lecturers or tutors motivate them in their study. The study was qualitative in nature and data were gathered through the open-ended questionnaires distributed to respondents.

In the foreign scenario , Guilloteax \& Dornyei [21] examined the link between teachers' motivational teaching practice and their students' language learning motivation. The findings based on 40 ESOL classrooms in South Korea that involved 27 teachers and more than 1300 learners show there were positive correlations between the teacher and student in the context of L2 motivation i.e. the results indicate that the language teachers' motivational practice is linked to increased levels of the learners' motivated learning behavior as well as their motivational state.

In addition, Chen [22] on her research on motivation and possible selves on Taiwanese EFL learners find seven out of 26 interviewees clarified their future plans in terms of their academic development and/ or their future preferred occupation. Other students were uncertaint about their future self-images since they themselves have different versions of future self-images. Among these seven respondents interviewed, not all of them have a genuine idea on the ideal L2 self. This is because one's personal concept and his social influences affect his possible self. Therefore, different individuals may face have different concepts and social influences. Her findings on the respondents through an interview also reveal that the ought-to-self in the study appears to deviate from its original theoritical definition of the concept. The ought to-self refers to 'the attributes that 
one believes one ought to possess as a results of perceived duties, obligations or responsibilities," [23]. In addition, the result of the interview also shows there was an existence of a dual focus of getting a promotion (rewarded) and prevention-focus instrumentality in their effort of learning English. One reason to explain this is because of the participants' own perception on the concept of ought-to self.

Sayadian \& Lashkarian [24] on their study to 657 students (randomly chosen) using the Attitude Motivation Test Battery (AMTB), Gardner (1995) at Yazd University, Iran find that male and female students have low attitudes towards English speakers. Male and female were highly instrumentally and integratively motivated. Female learners have greater instrumental and integrative motivation. Parents encouraged their children in their FL learning and students from the Engineering faculty have high attitudes to EFL as compared to students from Natural Resources Faculty. Overall result shows that learners are instrumentally motivated in their EFL.

In a study on Engineering students in South East Asia and beyond, Law, Sandnes \& Huang ([25] find learning correlates with motivation constructs. The motivation constructs investigated in their study are the intrinsic motivation (individual attitudes and motivation) and extrinsic motivation (challenging goals, the pulling forces, punishment, group pressure and learning approach). Respondents had high positive motivating effects on other motivation constructs except punishment. The step wise regression model used also showed that all the five motivating factors entered into this regression method. Therefore, it can be concluded that 'pulling forces' and 'group pressures' which are the extrinsic factors are the two determinants for motivating team-based and action-based learning. In addition, 'individual attitudes and expectations' has the highest mean among the five constructs which is 5 and this shows that it is an important motivator role.

From their study, Hassan, Imran, Muhammad Aslam \& Kasif [26] find extrinsically motivated students performed less in their academic performance as compared to intrinsically motivated students. Extrinsically motivated students performed well when they were rewarded after getting good grades in quizzes, but when they were not rewarded their extrinsic motivation level dropped. On the other hand, intrinsically motivated students really worked hard since they learned because they were interested in what they were doing. Since they are interested in their learning, they worked hard to achieve their goals. The conclusion made on their study is that "academic performance is positively influenced by intrinsic motivation and negatively affected by extrinsic motivation."

\section{Methods/SugGeStions to InCREASE Motivation SPIRIT AMONG LEARNERS}

Learning group setting and learning objectives should be taken into consideration when designing a new course for learners. Learners should be allowed to work in groups so that the 'pulling forces' like the rewards, achievement and clear goals can take place When working in groups, 'group pressure' will exist whereby the students will try their best to contribute to the work done in groups. It is important to create an environment that requires group or peer pressure in order to motivate learners in their learning [27].

Besides, a supportive learning environment should also be provided, so that learners will feel motivated to learn. A learning environment that is less threatening can encourage students' participation in class. "Creating a less threatening atmosphere to reduce anxiety and encouraging students to increase perceived competence may be effective in increasing willingness to communicate and frequency of L2 use in classrooms with Japanese ESL students. Perceived competence had a direct and strong influence on motivation, which in turn affected L2 communication frequency in the classroom. It may be especially important with the Japanese ESL students to increase perceived competence," [28].

Positive verbal encouragement and praise are important in learning because they can influence students' motivation. A student's self confidence can be built and improved through praises for effort and improvement [29]. Therefore, in class, teachers should apply appropriate praising methods that can further encourage students' participation, so that they will not be afraid to share and discuss ideas that they have. When students are comfortable with their learning environment, they will be more motivated to learn and attend classes besides doing well in the subject learnt.

Moreover, other activities that relate to L2 learning should be planned well so that learners will have the opportunity to participate. For instance, a 'homestay' program for exchange students may help to motivate learners to improve their target language proficiency. Teachers have duties to ensure that learning is interesting. They should create an interesting learning environment with activities that encourage students' participation. Teachers can use interesting texts to capture the students' interest and in the end this can help to increase their motivation level [30].

Second language learning motivation (SLLM) can also be enhanced by teachers when they use materials from other parts of the world. By doing this, students will be more interested in their learning since they will learn more about others customs, language, food people and environment [31]. Students are already aware of their own surrounding and culture, therefore when teachers integrate learning with materials that are not local, students will feel more interested to learn and to discover what others culture is all about. What makes them different and also what makes them the same.

\section{CONCLUSION}

Motivation undoubtedly plays a critical part in learners' language learning process. There are many theories of motivation that have been derived through the years. Each theory makes its contribution to research even if it has its own limitations. Different researchers have different findings and their researches are also based on different theories. Teachers and educators can benefit from their research findings to help learners achieve positive learning outcomes. Teachers can improvise and enhance their teaching methods, so that learners acquire the necessary skills to achieve their learning objectives. 


\section{REFERENCES}

[1] R. C. Gardner, Social psychology and second language learning, London: Edward Arnold, pp. 50, 1985.

[2] M. A. M. Moiinvaziri. (2007). Motivational orientation in English language learning. Summary: A study of Iranian undergraduate students' motivational orientation in English language learning. [Online]. Available: http://usingenglish.com/articles/ motivational-orientation-in-english-language

[3] Z. Dörnyei, Motivational strategies in the language classroom, UK: Cambridge University Press, pp. 1, 2001.

[4] R. M. Ryan and E. L. Deci, "Intrinsic and extrinsic motivations: Classic definitions and new directions," Contemporary Educational Psychology, vol. 25, pp. 54-67, 2000.

[5] D. Thanasoulas. (June 2001). Motivation as a contributing factor in second language acquisition. The Internet TESL Journal. [Online]. VII (6). pp. 1-7. Available: http://teslj.org/

[6] R. C. Gardner and W. E. Lambert, "Motivational variables in second language acquisition," Canadian Journal of Psychology, vol. 13, pp. 266-72, 1959.

[7] S. Sayadin and A. Lashkarian, " Investigating attitude and motivation of Iranian university learners toward English as a Foreign Language, Contemporary Issues in Education Research," ProQuest Education Journals, vol. 3, no. 1, pp. 137-147, Jan. 2010.

[8] C. Kelly. A Review of Traditional and Current Theories of Motivation in ESL. [Online]. Available: http://www.osaka-gu.ac.jp/php/kelly/ papers/motivation.html

[9] Z. Dörnyei. Motivation, Language Identity and the L2 self. [Online] Available: 2009-dornyei-mm.pdf

[10] E. L. Deci and R. M. Ryan, "Self-Determination Theory: A Macrotheory of Human Motivation, development and health," Canadian Psychology, vol. 48, no. 3, pp. 182-185, 2008.

[11] R. M. Ryan and E. L. Deci, "Intrinsic and extrinsic motivations: Classic definitions and new directions," Contemporary Educational Psychology, vol. 25, pp. 54-67, 2000.

[12] R. J. Vallerand, “Advances in Experimental Psychology,” M. P. Zanna, Ed., San Diego, California: Academic Press, 1997, pp.271-360.

[13] A. Yahya. (2006). Self concepts and motivation. UTM Institutional Repository. [Online]. Available: http://eprints.utm.my/5992/

[14] Z. Dörnyei, The psychology of the language learner: Individual differences in second language acquisition, New Jersey: Lawrence Erlbaum Associates, Inc., Publishers, 2005, pp. 105-106.

[15] Z. Dörnyei, "Motivation in second and foreign language learning," Language Teaching, vol. 3, no. 1, pp. 117-135, July 1998.

[16] S. Gas and L. Selinker, Second language acquisition: An introductory course, NJ: Lawrence Erlbaum Associates, Inc., Publishers, pp. 349, 2001.

[17] S. Bidin, K. Jusoff, N. A. Aziz, M. M. Salleh, and T. Tajudin, "Motivation and attitude in learning English among UiTM students in the Northern region of Malaysia," English Language Teaching, vol. 2, no. 2, June 2009.

[18] L. Nikitina and F. Furuoka, "Integrative motivation in a Foreign Language Classroom: A Study on the Nature of Motivation of the Russian Language Learners in Universiti Malaysia Sabah,” Jurnal Kinabalu, Jurnal Perniagaan \& Sains Sosial, vol. 11, pp. 23-34, 2005.

[19] Y. S. Mun, "Motivation as a contributing factor in English language learning: a comparison between different English language proficiency UTM undergraduates," unpublished undergraduate thesis, UTM Malaysia, 2004.

[20] L. S. Wei, T. F. T. Sulaiman, W. Mohamad, and Z. A. Kasim, "Motivation and study habits of working adults: A case study of Masters students in Open University Malaysia," in Proc. Conference Proceeding in International Conference of Lifelong Learning, Kuala Lumpur, November 2011, pp. 14-15,
[21] M. J. Guilloteax and Z. Dörnyei, "Motivating language learners: A classroom-oriented investigation of the effects of motivational strategies on student motivation," TESOL Quarterly, vol. 42, no. 1, pp. 55-77, 2008

[22] S. Chen, "Motivation and possible selves: An interview study of Taiwanese EFL learners," Language Education in Asia, vol. 3, no. 1, pp. 50-59, 2012.

[23] Z. Dörnyei, The psychology of the language learner: Individual differences in second language acquisition, New Jersey: Lawrence Erlbaum Associates, Inc., Publishers, pp. 105-106, 2005.

[24] S. Sayadin and A. Lashkarian, "Investigating attitude and motivation of Iranian university learners toward English as a Foreign Language, Contemporary Issues in Education Research," ProQuest Education Journals, vol. 3, no. 1, pp. 137-147, Jan. 2010.

[25] K. Law, F. E. Sandnes, H. Jian, and Y. Huang, “A comparative study of learning motivation among Engineering students in South East Asia and beyond," Research Express@NCKU, vol. 10, no. 7, pp. 1-4, 2009.

[26] I. Ali, M. A. Khan, and K. Hamid, "A study of university students' motivation and its relationship with their academic performance," International Journal of Business and Management, vol. 5, no. 4, pp. 80-88, April 2010.

[27] K. Law, F. E. Sandnes, H. Jian, and Y. Huang, "A comparative study of learning motivation among Engineering students in South East Asia and beyond," Research Express@NCKU, vol. 10, no. 7, pp. 1-4, 2009.

[28] Y. Hashimoto, "Motivation and willingness to communicate as predictors of reported L2 use: The Japanese ESL context," Second Language Studies, vol. 20, no. 2, pp. 29-70, Spring, 2002.

[29] K. C. Williams and C. C. Williams, "Five key ingredients for improving student motivation," Research in Higher Education Journal, vol. 12, pp. 1-23, August 2011.

[30] D. Thanasoulas. (June 2001). Motivation as a contributing factor in second language acquisition. The Internet TESL Journal. [Online]. VII (6). pp. 1-7. Available: http://teslj.org/

[31] M. Shahbaz and Y. Liu, "Complexity of L2 motivation in an Asian EFL setting," Porta Linguarium, vol. 18, pp. 115-131, June 2012.

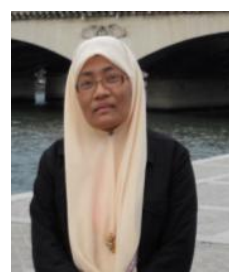

Surina Nayan has a diploma in banking from Institut Teknologi MARA (ITM), bachelor Sc. in business (marketing) from Oklahoma State University, Stillwater, USA, Post-Graduate Diploma in TESL, ITM and MA in Linguistics -English Language Studies from Universiti Sains Malaysia. Currently, she is pursuing her doctoral degree at Universiti Utara Malaysia. Her research interests are on collaborative teaching and learning, second language learning and SLA. She is a member of ASIA TEFL.

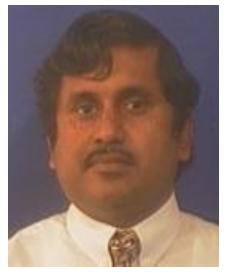

Hariharan N. Krishnasamy is a $\mathrm{PhD}$. He has been attached to Universiti Utara Malaysia since 1994 Currently, he teaches sociolinguistics and ESP courses. His research interests include intercultural communication, higher education and teacher education. Dr. Hariharan has presented in conferences and published papers on his field and also supervisors local and international students.

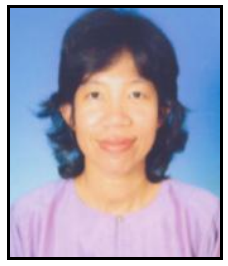

Latisha Asmaak Shafie was born in Malaysia in 1970 She received her bachelor of education in TESL (Hons.) from Universiti Kebangsaan Malaysia in 1993. She received her Master in Instructional Technology from Universiti Malaya in 2004. She is pursuing her doctorate at Universiti Utara Malaysia. Her research interests include learning technologies, second language learning, digital learners and computer mediated course. She is a member of ASIA TEFL. 